\title{
Ah4. (2)
}

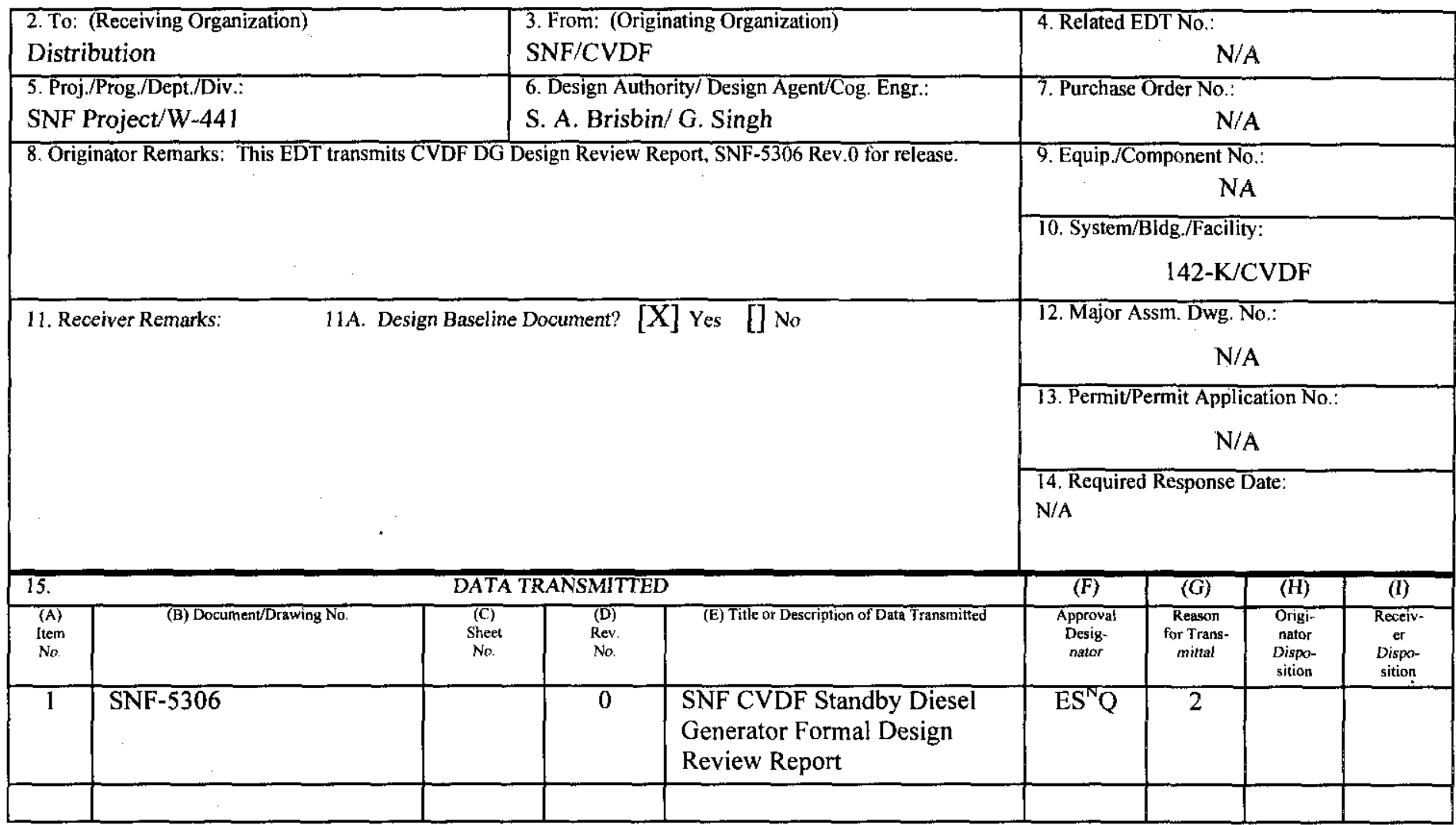

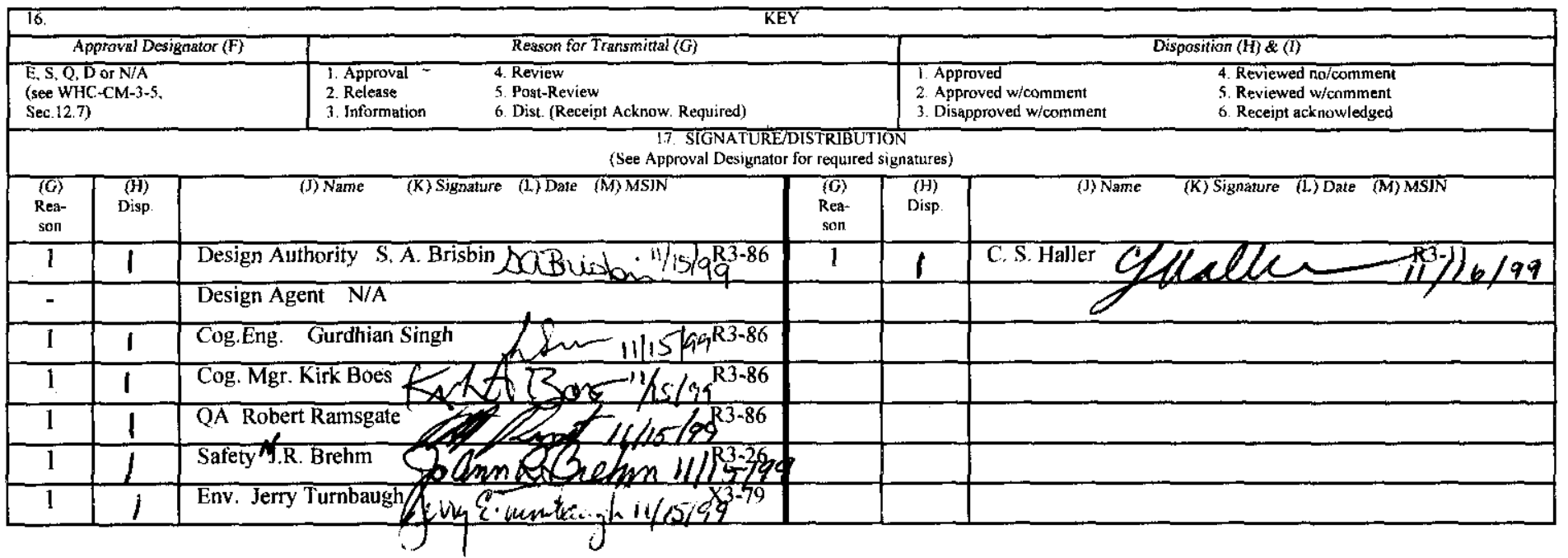
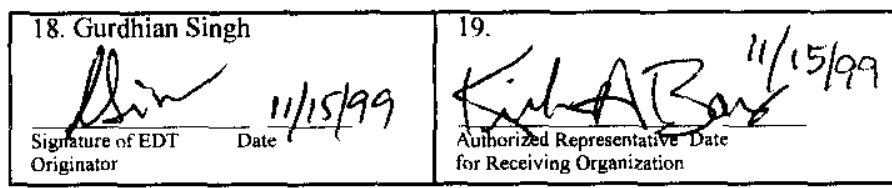

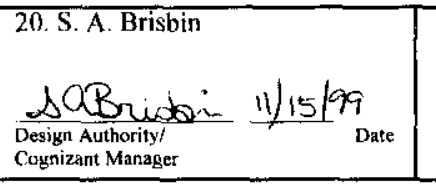

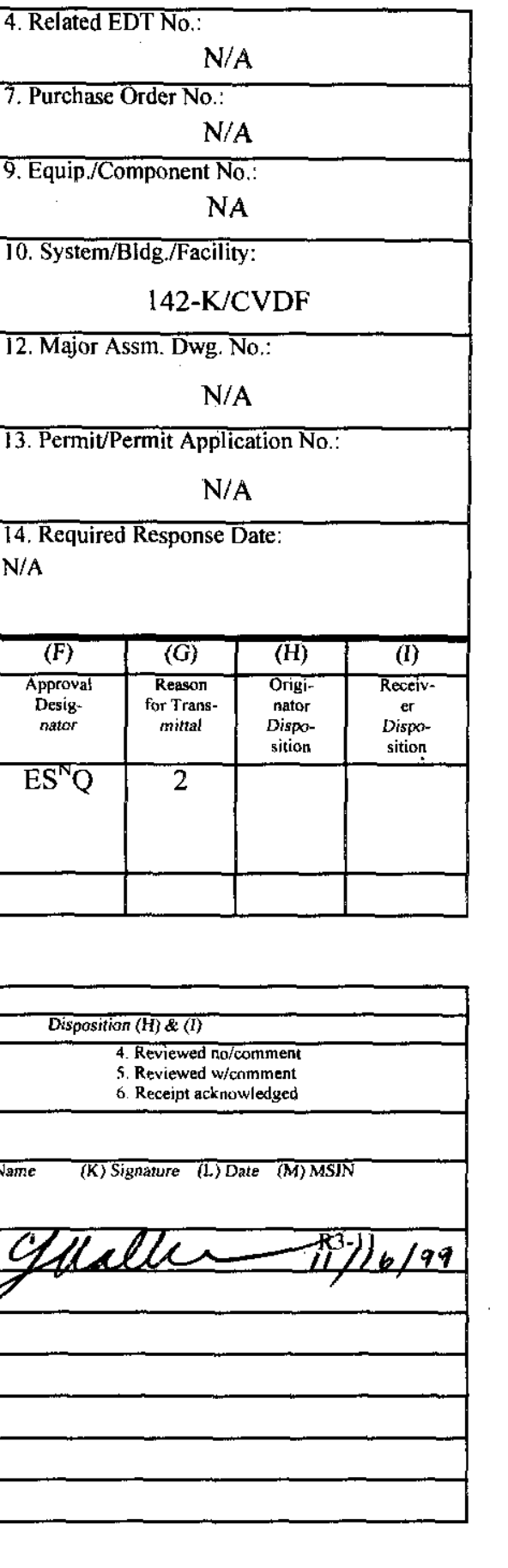

Ctrl. No.

[1] Approved

[] Approved w/comments

[] Disapproved w/comments

BD-7400-172-2 (05/96) GEF097 


\section{SNF-5306}

\section{REVISION 0}

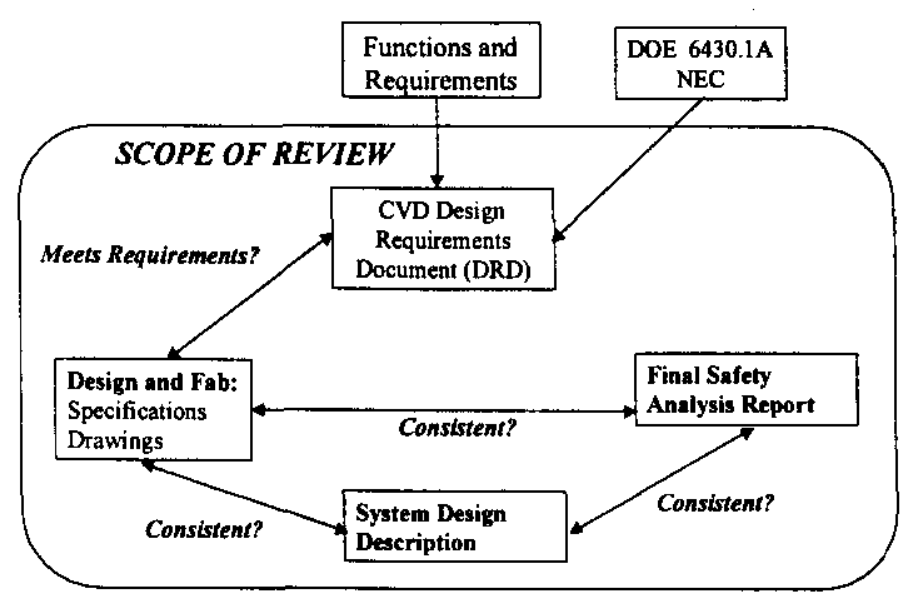

\section{Figure 2-1. Standby Diesel Generator Design Report Roadmap}

At the end of the review period, Review Comment Records (RCRs) with significant comments from the review team were discussed in a meeting. The RCRs were submitted to the Architect-Engineer (A-E), Meier Enterprises, Inc., for disposition.

The dispositions were received and concurrence reached by all reviewers (as shown in Appendix A). The A-E was directed to implement the RCR dispositions.

\subsection{Documents Reviewed}

The primary baseline documents provided by the Project Team for review defining the design requirements and design verification are as follows.

- Design Requirements

- CVDF DRD (HNF-SD-SNF-DRD-002, Rev. 4), Section 6.14.4.22.

- CVDF FSAR (HNF-3553, Rev. 0, Annex B), Section B4.4.7.

- CVDF TSR (HNF-3673, Rev. 0), Section 3.5.

- $\quad$ Safety Equipment List, HNF-SD-SNF-SEL-002 and Master Equipment List, SNF-4148. 
- $\quad$ Design Media

- H-1-83971, Sht. 1, Rev. 0, CVDF Generator Building Architectural Floor Plan, Elevations \& Details.

- H-1-83972, Sht. 1, Rev. 0, CVDF Generator Building Structural Plan, Elevations \& Details.

- H-1-83974, Sht. 1, Rev, 0, CVDF Generator Building Mechanical P\&ID.

- H-1-83975, Sht. 1, Rev, 0, CVDF Generator Building Mechanical Floor Plan \& Sections.

- H-1-83976, Sht. 1, Rev, 0, CVDF Generator Building Mechanical Details.

- H-1-83977, Sht. 1, Rev. 0, CVDF Generator Building Electrical Plan, Sections \& Details.

- H-1-83978, Sht. 1, Rev. 0, CVDF Generator Building Electrical One-Line Diagram \& Conduit Schedule.

- H-1-83978, Sht. 2, Rev. 0, CVDF Generator Building Electrical DG Connection Diagram.

- H-1-83979, Sht. 1, Rev. 0, CVDF Generator Building Electrical GND Plan, CND Plan \& Details.

- DCN-W-441-196 Rev. 0.

- DCN-W-441-247 Rev. 0.

- DCN-W-441-269 Preliminary.

- DCN-W-411-285 Preliminary.

- Equipment Procurement Specification, W-379-C-CSB-16200, Rev. 0, for the Canister Storage Building (CSB) Diesel Generator, Transfer Switch, Air Receiver Tank, and Diesel Fuel Tank.

\section{- $\quad$ Design Verification}

- MEI-2621 ST-16.A, Seismic analysis for diesel generator building.

- MEI -2621 ME-4, Freeze protection of the fire protection \& deionized water lines.

- MEI -2621 ME-5, Ventilation, heating and cooling requirements for the CVDF standby generator building.

- MEI -2621 ME-7, CVDF Load, fault and coordination analysis for the standby diesel generator.

- No Number - Lighting calculations for the standby diesel generator building for normal and emergency operation.

- Vendor Documentation

- Seismic calculations by Nutherm. 


\section{SNF-5306 \\ REVISION 0}

\subsection{RESULTS}

\subsection{Summary}

It is the consensus of the Design Review Team that the standby diesel generator should function as intended, and in doing so, should meet the needs of the (SNF) CVDF Project. follows:

The major comments received from the Design Review Team which require action are as

1. the deletion of the requirement to heat trace the piping from the diesel storage tank to the diesel day tank and to heat the diesel storage tank; removing the requirement to heat trace the sprinkler piping in the process bays (Appendix A, Page A-9, Comment $5)$, and

2. the relocation of the Diesel Generator Building away from the railroad tracks (Appendix A, Page A-15, Comment 4).

The design drawings, DRD, and the FSAR will require revisions to incorporate these changes.

\subsection{Overview and General Observations}

The design review resulted in RCR comments. The recommendations for the implementation of the dispositions are provided in Section 3.3.

The review focused on evaluation of the design with respect to three primary areas of interest: 1) adequacy of the design to meet requirements, 2) consistency between primary baseline documents, 3) FSAR technical content and consistency with design media. These areas, along with general observations and conclusions resulting from the review, are listed below. The summary observations are not exhaustive, but are intended to provide insight into impressions held by the Design Review Team after an intensive review of the documentation.

\subsubsection{Adequacy of Systems to Meet Requirements}

The Design Review Team has a good level of confidence that the standby diesel generator will meet the requirements of the DRD and function properly. This conclusion is the technical judgment of the team based on mid-level and detailed reviews performed. Reviews took into account requirements, drawings, regulations/codes, calculations, and test results.

\subsubsection{Consistency Between Primary Baseline Documents}

